\section{European Commission proposes public health department}

Rory Watson, Brussels

The European Commission is being urged to establish a specific department to handle public health issues.

The idea has been launched by Euro MPs at a meeting this week. They believe that the creation of a special health directorate general under the direct responsibility of one of the 20 commissioners would help to ensure that health concerns are placed at the heart of all European policy areas, ranging from agriculture to consumer affairs.

Supporters of the move acknowledge that responsibility for the organisation and delivery of health services will remain the next year. exclusive responsibility of national governments. But they point out that the coming into force of the new Amsterdam Treaty containing the latest changes to the EU's constitution in the next few weeks will commit the 15 member states to ensuring "a high level of human health protection."

The British Labour MEP Clive Needle, who won the support of the European parliament for the concept of a health commissioner, has also called for a European decade of health from

Euro MPs believe that three priorities should now feature prominently on the Union's health agenda: improvements in public health information, ensuring an ability to react rapidly to threats to health, and tackling health determinants through health promotion and disease prevention. To these will be added an increasing emphasis on the need to help raise health standards in those countries of Eastern and Central Europe that are hoping to join the Union.

The MEPs' recommendations will now be taken into account by EU governments as they finalise the Union's second health programme, which is due to start next year.

The suggestion coincides with moves to overhaul the European Commission's own internal bureaucracy, after the unprecedented mass resignation in mid March of the full team of 20 commissioners.

\section{Outbreak of Japanese encephalitis hits Malaysia}

Adam Easton, Manila

More than 50 people have died and hundreds of thousands of pigs-the possible carriers of the infection-have been slaughtered in Malaysia after an outbreak of Japanese encephalitis.

There have been 154 reported cases of Japanese encephalitis, of which 42 have been confirmed, and 56 deaths in Negeri Sembilan, $90 \mathrm{~km}$ south of the capital, Kuala Lumpur, and in Perak. Many of the victims were adult male pig farmers or workers. The outbreak has spread to neighbouring Singapore, where eight cases and one death have been reported.

The disease outbreak has caused panic among sections of the population. Up to 700 soldiers have reportedly entered three villages in Negeri Sembilan and begun shooting 300000 pigs. The pigs are the reservoir for the virus, which is commonly transmitted to humans via the Culex mosquito. Both Singapore and Thailand have banned the import of pigs from Malaysia.

Malaysia has suffered outbreaks of the virus previously and has adequate resources to deal with the current one according to the World Health Organisation's regional adviser in vector borne diseases, $\mathrm{Dr}$ Kevin Palmer. The country generally reports a handful of seasonal cases of Japanese encephalitis each year. The area currently affected has the highest density of pigs in South East Asia and an unusually large number of mosquitoes. Sanitation is also extremely poor, and some observers have been surprised that an outbreak has not occurred previously. Dr Palmer

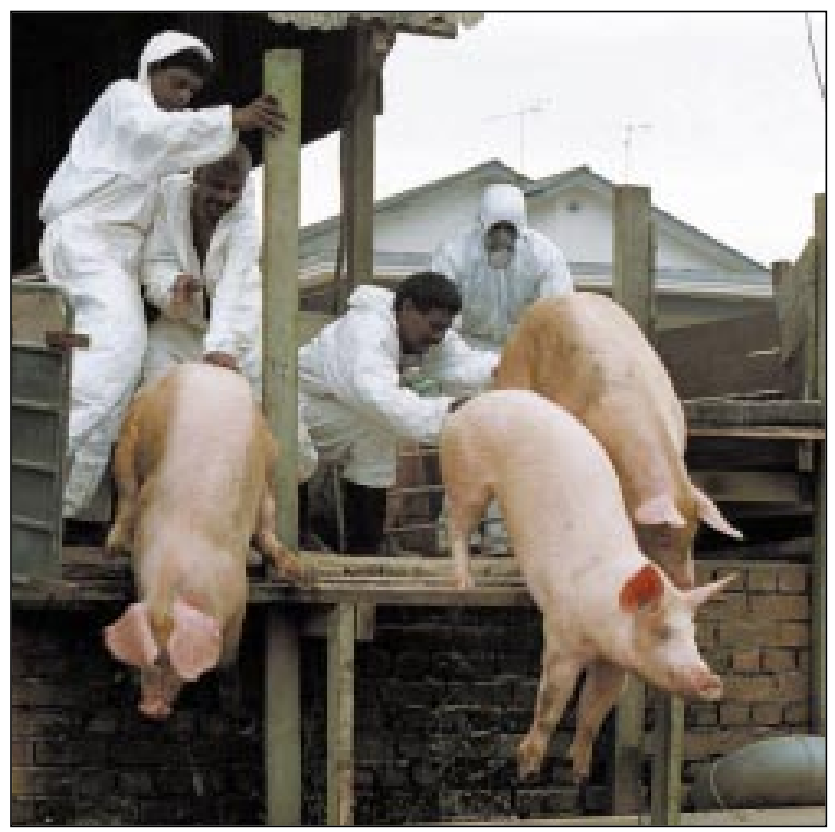

Pigs are being slaughtered to halt the spread of Japanese encephalitis

\section{Open letter disputes WHO hypertension guidelines}

Richard Woodman, London

Over 400 doctors, pharmacists, and scientists from 42 countries have signed a letter on the internet, expressing fears that the World Health Organisation's new hypertension guidelines will result in "increased use of antihypertensive drugs, at great expense and for little benefit."

The letter, to WHO Director General Gro Harlem Brundtland, says that there is insufficient evidence to justify the recommended guideline of restoring blood pressure to levels defined as "normal" $(<130 / 85 \mathrm{~mm} \mathrm{Hg})$ or "optimal" $(<120 / 80 \mathrm{~mm} \mathrm{Hg})$. "As far as we know, there is only one trial that has aimed to investigate the level of optimal target blood pressure, the Hypertension Optimal Treatment (HOT) study (Lancet 1998;351:1755-62). About the HOT study, the guidelines state: "Comparison of outcomes between the three randomised blood pressure target groups in the HOT study (diastolic blood pressure $\leqslant 90,85$ or $80 \mathrm{~mm} \mathrm{Hg}$ ) was unable to detect significant differences in the risk of cardiovascular disease between adjacent target groups. We have also reviewed the HOT paper and found no evidence to recommend aiming for a blood pressure below 140/90 in nondiabetic patients."

"The justification for the recommendation seems to be that the HOT study indicates that there is no increase in cardiovascular risk in patients randomised to the lowest target groups $(\leqslant 80 \mathrm{~mm} \mathrm{Hg})$. In our view it is necessary to prove benefit, not lack of harm, when making such a recommendation."

Ingrid Martin, the team coordinator for cardiovascular disease at the WHO in Geneva, commented: "The recommendations represent the guidelines committee's interpretation of the totality of the available evidence from epidemiological studies and from randomised trials." $\square$

The letter can be read at www. uib.no/isf/letter/ 